\title{
A retrospective study of community-acquired Salmonella infections in patients attending public hospitals in Lagos, Nigeria
}

\author{
Kabiru O. Akinyemi ${ }^{1}$, Yetunde O. Oshundare ${ }^{1}$, Oladeji G. Oyeyinka ${ }^{1}$, Akitoye O. Coker $^{2}$ \\ ${ }^{1}$ Department of Microbiology, Lagos State University, Ojo PMB 1087, Apapa, Lagos, Nigeria \\ ${ }^{2}$ Department of Medical Microbiology and Parasitology, College of Medicine, University of Lagos, Idi-Araba, PMB \\ 12003, Lagos, Nigeria
}

\begin{abstract}
Introduction: A retrospective cohort study on Salmonella-associated diseases (SADs) was conducted in 14 public hospitals across Lagos State, Nigeria, between 1999 and 2008.

Methodology: Medical records of clinically diagnosed patients with confirmed Salmonella infections were reviewed for the 10-year period. Laboratory diagnosis of typhoid fever cases in all the hospitals were first based on Widal agglutination tests then followed by culture, while non-typhoidal Salmonella infections were based on culture technique.

Results: A total of 85,187 confirmed cases of SADs were found, of which 880 deaths were recorded (case-fatality rate $=1.03 \% / 10$ years). The mean incidence of SADs in Lagos State for the 10-year period was estimated at 45 cases per 100,000 persons/year, while that of typhoid fever alone was 16 cases per 100,000 persons/year. During the studied period, the number of deaths due to typhoid fever was significantly (P $<0.05$ ) higher than deaths due to gastroenteritis except in 2003 and 2004. Risk associated with typhoidal deaths was 4 to 11 times greater when compared to gastroenteritis deaths between 2000 and 2002. Salmonella-associated diseases were most prevalent in adults 21 -to30 years of age (49.49\%). Cases of patients with invasive Salmonella-associated gastroenteritis were observed mainly in children under five years of age.

Conclusion: The current surveillance data indicated high incidence of SADs in areas exposed to environmental contaminations. This study revealed that infections caused by Salmonella enterica serovars are endemic in our environment thus poses a serious threat to public health. Constant public health education is essential to avert undue epidemics.
\end{abstract}

Key words: Salmonella; diseases; retrospective; typhoid fever; gastroenteritis; medical records

J Infect Dev Ctries 2012; 5(6):387-395.

(Received 15 June 2011 Accepted 10 August 2011)

Copyright $($ C 2012 Akinyemi et al. This is an open-access article distributed under the Creative Commons Attribution License, which permits unrestricted use, distribution, and reproduction in any medium, provided the original work is properly cited.

\section{Introduction}

The true incidence of Salmonella-associated diseases (SADs) in humans is difficult to evaluate because of lack of an epidemiological surveillance systems, especially in developing countries. Each year, there are 12 to 33 million cases of typhoid fever worldwide [1]. In the United States and most European countries, epidemic typhoid is predominantly a disease of travelers returning to their home countries from endemic areas [2]. There are 1.4 million cases of nontyphoidal salmonellosis annually, resulting in 168,000 visits to physicians, 15,000 hospitalizations and 580 deaths [3] and 500 cases of typhoid fever in the USA [1]. Typhoid fever is endemic throughout Africa and Asia and persists in the Middle East, a few Southern and Eastern European countries and Central and South America [4]. In Nigeria, typhoid fever is among the major widespread diseases affecting both young children and young adults as a result of many interrelated factors such as inadequate facilities for processing human wastes and indiscriminate use of antibiotics [5,6]. Morbidity associated with illness due to Salmonella continues to be on the increase, in some cases resulting in death [5]. It is difficult to evaluate SADs burden because of the very limited scope of studies the lack of coordinated epidemiological surveillance systems at all levels of government (federal, state and local), and the presence of other diseases considered to be of higher priority. These situations have undermined reported cases of waterborne infections, particularly typhoid fever. Sporadic outbreaks of typhoid fever often cause widespread enteritis among urban and rural communities [7]. Over the years reliable epidemiological data from which to estimate the 
burden of SADs in Lagos State has become obscured, because most of the public hospitals in the state found it difficult to make data available, where it existed, to appropriate agencies for proper documentation, planning and interventions. This study was initiated with a view to generate information through a coordinated epidemiological surveillance study from which SADs burden in Lagos could be assessed. To our knowledge this is the first report of a large population-based retrospective cohort study on laboratory-confirmed Salmonella infections in recent years in Lagos Nigeria.

\section{Methodology}

Ethical approval

Ethical approval was through the ethical committee of the Institution and permission from Lagos State Ministry of Health

\section{Study design}

A 10-year retrospective cohort study on SADs was conducted in Lagos State, Nigeria, between 1999 and 2008. Fourteen prominent public hospitals across the state were used as study areas and are as follows: Ikeja General Hospital (IGH), Badagry General Hospital (BGH), Apapa General Hospital (AGH), Isolo General Hospital (IGH), Surulere General Hospital (SGH), Ikorodu General Hospital (KDGH, Ebute-Metta General Hospital (EBGH), Orile-Agege General Hospital (OAGH), Lagos-Island General Hospital (LGH), Gbagada General Hospital (GGH), Mainland (Yaba) General Hospital (MGH), Ajeromi General Hospital (AJGH), Agbowa General Hospital (AWGH) and Epe General Hospital (EGH). These hospitals served as referral centres for both inpatients and out-patients in all the local government council areas of the state. Medical records of clinically diagnosed patients with confirmed Salmonella infections were reviewed for the 10-year period.

\section{Case definition and data collection}

The medical records of these hospitals categorized Salmonella-associated diseases as typhoid fever, gastroenteritis, food poisoning, septicemia and psychosis. Typhoid fever cases were diagnosed by clinicians as having pyrexia for up to five days or more with one or more of the following symptoms: diarrhoea, vomiting, loss of appetite, persistent headache, and malaise. Gastroenteritis cases were diagnosed by the physician as having intestinal disorder and/or frequent passing of stool.
Some patients were also observed with complications such as psychosis and septicemia. Demographic data such as age, sex, underlying conditions of the patients, number of death cases, and vaccination status were recorded. Nationality of the patients and countries visited during the month before onset of infection (travel-associated cases) could not be derived.

Procedures used to process samples collected from patients throughout the 10-year period in all the hospitals

Several attempts were made at source identification to ensure compliance with the standard procedures in each of these hospitals. Laboratory diagnosis for typhoid cases in all the hospitals were first based on Widal agglutination tests and confirmation by bacteriological analysis of blood, bone marrow, and stool and/or urine samples of the patients. The Widal test was performed with standardized Salmonella enterica serovar Typhi O and $\mathrm{H}$ antigens and values more than the cutoff titre value (1:160 for $\mathrm{O}$ and $\mathrm{H}$ agglutinins) were regarded as positive. Blood samples were inoculated into brain-heart infusion broth in a ratio of $1: 9$ and incubated at $37^{\circ} \mathrm{C}$. Subculture was made on the following media: blood agar (Oxoid, London,UK) MacConkey's agar (Oxoid) and Salmonella-Shigella agar (Oxoid). Stool samples from cases of gastroenteritis were cultured directly on solid media. All culture plates were incubated aerobically at $37^{\circ} \mathrm{C}$ for 24 hours. Colonies were first Gram stained and then subjected to biochemical tests as described by Cowan and Steel [8]. None of the hospitals performed serotyping of the Salmonella isolates.

\section{Statistical analysis}

F-statistics calculating analysis of variance using the SPSS 11.0 Statistical Package (IBM, Chicago, USA) were computed to test the distribution of cases of Salmonella infections for the 10-year period.

\section{Results}

Out of 85,187 confirmed cases of Salmonellaassociated diseases (SADs), 880 deaths were recorded between 1999 and 2008 in 14 public hospitals in Lagos State, giving a case-fatality rate of $1.03 \%$. The highest cases of SADs were recorded in Ikeja General Hospital followed by Ebute-Metta General Hospital, and the least in Isolo General Hospital. Figure 1 shows that the highest percentage $(41.1 \%)$ of the total deaths recorded in this study was 
Figure 1. Number of Salmonella-associated cases and deaths recorded in 14

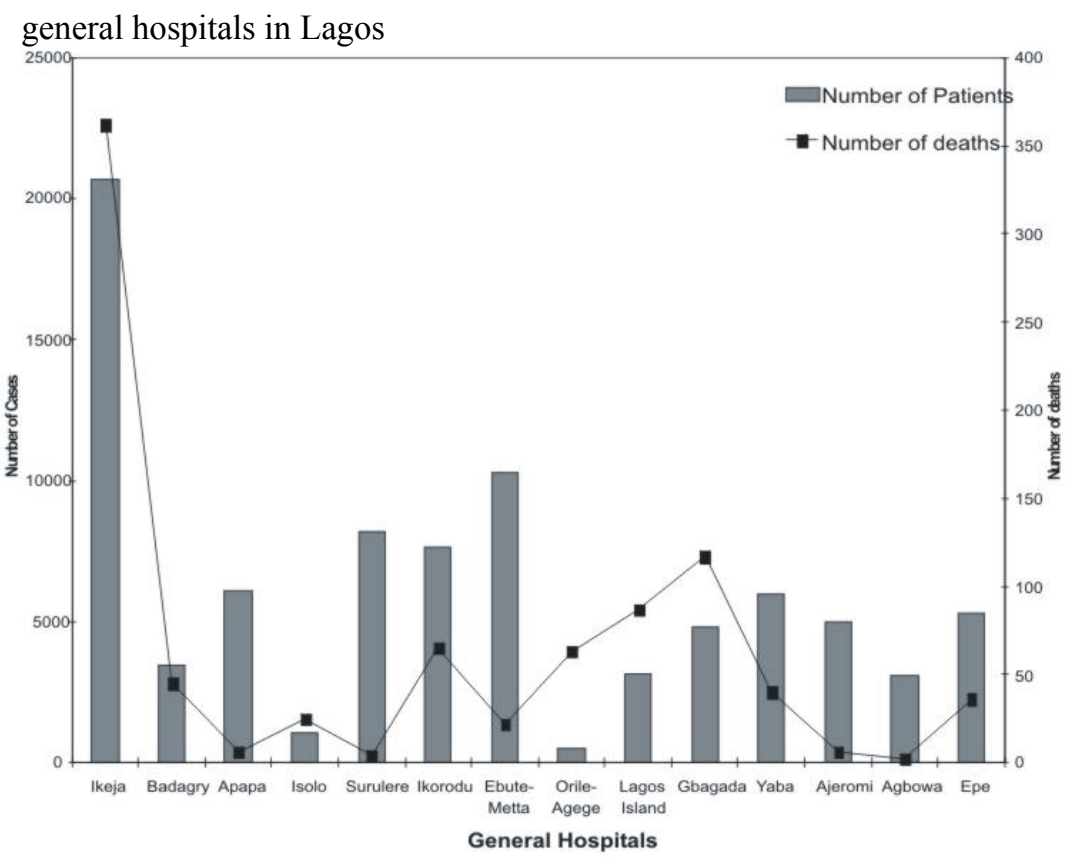

observed in Ikeja gGeneral Hospital followed by $13.3 \%$ in Gbagada Hospital, while the lowest percentage of deaths was recorded in Surulere Hospital $(0.5 \%)$. The prevalence of non-typhoidal Salmonella-associated illness in this study was $64.5 \%$ as compared to $35.5 \%$ recorded for typhoid fever. The mean incidence of SADs in Lagos State with a population of about 19 million people for the 10 -year period was estimated to be 45 cases per 100,000 persons per year, while that of typhoid fever and gastroenteritis were 16 cases per 100,000 persons per year and 29 cases per 100,000 persons per year respectively (Table 1). The number of female patients with septicemia was significantly higher $(\mathrm{P}<0.05)$ than that of male patients, and the psychotic Salmonella-infected males in this study did not significantly $(\mathrm{P}>0.05)$ outnumber their female counterparts; however, the risk of septicemia cases could be as much as five times higher than that of psychosis patients (Table 2). During the period from1999 to 2008, deaths due to Salmonella infections occurred in patients with typhoid fever and gastroenteritis. The number of deaths due to typhoid fever was significantly $(\mathrm{P}<0.05)$ higher than deaths due to gastroenteritis except in 2003 and 2004. The risk associated with typhoidal deaths was between 4 and 11 times higher when compared to gastroenteritis deaths between the years 2000 and 2002 (Table 3). Both diseases showed an increasing trend in both sexes between 1999 and 2001. The increase in trends of both diseases was recorded in male subjects between years 2002 and 2006 and in female subjects between the years 2003 and 2004. The highest number of typhoid cases and deaths occurred in females in 2006 (Table 4).

Salmonella-associated diseases were most prevalent in adults 21 to 30 years of age $(49.49 \%)$, followed by the age group 31 to 40 years $(16.0 \%)$, while the lowest percentage of Salmonellaassociated diseases was found in the age group 11 to 20 years $(7.30 \%)$. More cases were observed in the year $2006(17.8 \%)$ than in any other year during the period under review (Figure 2). Few cases of patients with invasive Salmonella-associated gastroenteritis were observed, and these were mainly in children under five years of age. Also, infants and children aged 0-10 years was the third age group most affected by SADs; this group accounted for $17.7 \%$ cases and $33.5 \%$ death of typhoid fever in this study (Table 5).

\section{Discussion}

Salmonella infection in humans continues to be a distressing health problem. The results of a 10-year retrospective cohort study conducted in 14 public hospitals in Lagos revealed 85,187 confirmed cases of Salmonella-associated diseases (SADs), of which 880 deaths were recorded, giving a case-fatality rate of $1.03 \%$. Of the 85,187 patients, 54,919 (64.5\%) had gastroenteritis and 30,210 (35.5\%) had typhoid fever (Table 2). These results indicate that infections caused by Salmonella enterica serovars are endemic 
Table 1. Incidence of Salmonella-associated diseases from 1999-2008 in Lagos State

\begin{tabular}{|l|c|c|c|}
\hline $\begin{array}{c}\text { Salmonella- } \\
\text { associated diseases }\end{array}$ & $\begin{array}{c}\text { Number of } \\
\text { cases }\end{array}$ & $\begin{array}{c}\text { Incidence/10 } / \mathbf{Y r} \\
\left(\mathbf{p = 1 9} \times \mathbf{~ 1 0}^{\mathbf{5}}\right)\end{array}$ & $\begin{array}{c}\text { Number of } \\
\text { deaths }\end{array}$ \\
\hline Gastroenteritis & 54,919 & 29 & $\mathbf{6 5 3}$ \\
Typhoid fever & 30,210 & 16 & $\mathbf{2 2 7}$ \\
Septicaemia & 48 & 0.005 & $\mathbf{0}$ \\
Psychosis & 10 & 0.001 & $\mathbf{0}$ \\
Total & $\mathbf{8 5 , 1 8 7}$ & $\mathbf{4 5}$ & $\mathbf{8 8 0}$ \\
\hline
\end{tabular}

Table 2. Relative risk of Salmonella-associated diseases in male and female subjects in Lagos

\begin{tabular}{|l|l|l|l|l|}
\hline $\begin{array}{l}\text { Salmonella- } \\
\text { associated diseases }\end{array}$ & $\begin{array}{l}\text { Number of } \\
\text { males (\%) }\end{array}$ & $\begin{array}{l}\text { Number of } \\
\text { females (\%) }\end{array}$ & $\begin{array}{l}\text { Total Number } \\
\mathbf{( \% )}\end{array}$ & $\begin{array}{l}\text { Male vs Female } \\
\chi \mathbf{2}, \mathbf{P}[\mathbf{R R}(\mathbf{9 5 C I})]\end{array}$ \\
\hline Typhoid fever & $17,610(35.4)$ & $12,600(35.6)$ & $30,210(35.5)$ & $0.57,0.4[0.99(0.99-1.02)]$ \\
Gastroenteritis & $32,168(64.6)$ & $22,751(64.3)$ & $54,919(64.5)$ & $0.75,0.4[1.01(0.98-1.04)]$ \\
Septicaemia & $20(0.04)$ & $28(0.08)$ & $48(0.06)$ & $5.58,0.01[0.51(0.28-0.93)]$ \\
Psychosis & $6(0.01)$ & $4(0.01)$ & $10(0.01)$ & $0.01,0.92[1.07(0.27-4.48)]$ \\
Total & $49,804(100.0)$ & $35,383(100.0)$ & $85,187(100.0)$ & $0.68,0.4[0.99(0.97-1.03)]$ \\
\hline
\end{tabular}

$\mathrm{RR}=$ relative risk statistics; $95 \mathrm{CI}=95 \%$ confidence intervals; $\mathrm{P}=$ probability $; 2=$ Chi square 
Figure 2. Age distribution of cases of Salmonella-associated diseases in Lagos (1999-2008)

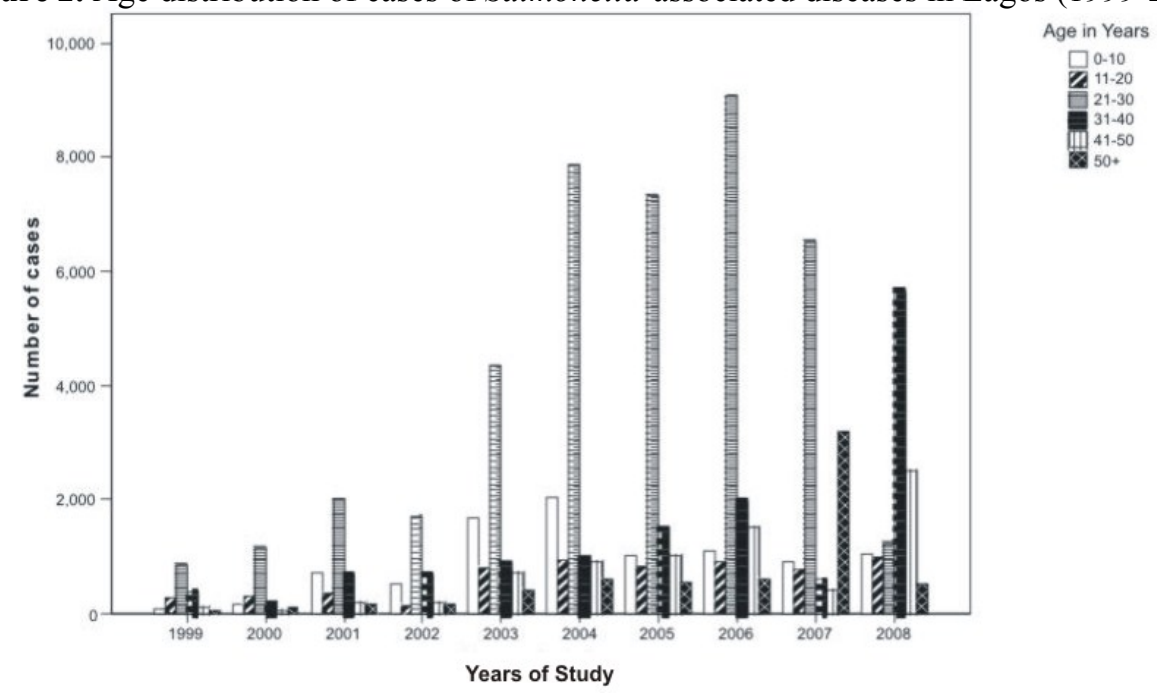

in our environment and thus pose a serious threat to public health. In many developing countries, typhoid and paratyphoid are major causes of gastric illness transmitted by the faecal-oral route $[9,10]$. In Thailand, Salmonella are the main bacteria which cause gastrointestinal and systemic infections. In 2005 alone, nontyphoidal Salmonella contributed $89.39 \%$, of SADs followed by typhoidal salmonellosis [11]. Recently, Salmonella-associated diarrhoea and fever was reported in Maseno, Kenya [12]. The severe disease has poor prognosis because of co-infection and co-endemicity with malaria $[7,9]$. Although no cases of typhoid perforations and hepatomegally were found in our study, a few cases of life-threatening complications such as septicemia $(48 ; 0.06 \%)$ and typhoid psychosis $(10 ; 0.01 \%)$ were noticed. Typhoid fever complications such as septicemia, typhoid psychosis, intestinal perforations, hepatosplenomegaly and haemorrhage have been documented to increase mortality in areas characterized by inadequate sanitation, poor hygienic practices, and drug abuse $[5,7,13]$.

In this study, the mean incidence of SADs for the 10 -year period was estimated to be 45 cases per 100,000 per year, while that of typhoid fever alone was 16 cases per 100,000 persons per year (Table 1). To our knowledge, no previous studies have examined the population-based surveillance at all the public hospitals for laboratory-confirmed Salmonella infections in Lagos State, Nigeria. In Mediterranean African countries, typhoid fever is considered endemic with medium incidence of 10 to 100 cases per 100,000 persons $[14,15]$ and in Libya the incidence rate for the year 2006 was 16 per 100,000 persons per year [16]. Egypt remains a country with intermediate incidence of one to 180 per 100,000 cases of enteric fever, below nations such as India and Indonesia which claimed more than 100 cases per 100,000 persons [17]. In Tunisia, the 2006 Bulletin of the Ministry of Health showed an incidence of typhoid fever of about one case per 100,000 per year [18]. Also, recent data in Morocco indicated an estimate of 8 cases per 100,000 of typhoid fever [19]. Therefore, the high incidence of SADs, particularly of typhoid fever recorded in the present study, may represent a surveillance artifact resulting from increased awareness of the diseases, greater access to diagnostic facilities, more sensitive diagnostic methods, and good record and reporting systems in the health-care facilities examined.

The number of deaths arising from SADs was not proportional to the number of cases in all hospitals but Ikeja General (Figure 1). During the 10-year period, deaths due to Salmonella infections occurred in patients with typhoid fever and gastroenteritis. The number of deaths due to typhoid fever was significantly $(\mathrm{P}<0.05)$ higher than deaths due to gastroenteritis except in 2003 and 2004. The risk associated with typhoidal deaths was between 4 and 11 times higher when compared to gastroenteritis deaths between the years 2000 and 2002. Available records revealed that most patients were from low socio-economic status, residing in areas with poor sanitation. The current surveillance data indicated 
Table 3. Types and numbers of cases and deaths of Salmonella-associated diseases in Lagos for 10-year period (1999-2008)

\begin{tabular}{|c|c|c|c|c|c|c|}
\hline Years & $\begin{array}{r}\text { Typhoid fever } \\
\text { (deaths) }\end{array}$ & $\begin{array}{r}\text { Gastroenteritis } \\
\text { (deaths) }\end{array}$ & RR (95\%CI) & $\begin{array}{r}\text { Septicemia } \\
\text { (deaths) }\end{array}$ & $\begin{array}{r}\text { Psychosis } \\
\text { (deaths) }\end{array}$ & $\begin{array}{l}\text { Total number of } \\
\text { patients (deaths) }\end{array}$ \\
\hline 1999 & $445(13)$ & $1,294(17)^{*}$ & $2.3(1.0-5.0)$ & $13(0)$ & - & $1,752(30)$ \\
\hline 2000 & $536(15)$ & $1,422(10)^{*}$ & $4.1(1.7-9.8)$ & - & - & $1,958(25)$ \\
\hline 2001 & $1,342(10)$ & $2,767(2)^{*}$ & $11.2(2.3-74.2)$ & $11(0)$ & - & $4,120(12)$ \\
\hline 2002 & $906(8)$ & $2,483(3)^{*}$ & $7.4(1.8-35.2)$ & $4(0)$ & $5(0)$ & $3,398(11)$ \\
\hline 2003 & $3,337(27)$ & $5,558(51)$ & $0.9(0.5-1.4)$ & $2(0)$ & - & $8,897(78)$ \\
\hline 2004 & $4,367(57)$ & $8,983(113)$ & $1.0(0.7-1.5)$ & - & - & $13,350(170)$ \\
\hline 2005 & $4,313(30)$ & $7,901(84)^{*}$ & $0.7(0.4-1.0)$ & $10(0)$ & $1(0)$ & $12,225(114)$ \\
\hline 2006 & $4,467(20)$ & $10,700(180)^{*}$ & $0.3(0.2-0.4)$ & - & $3(0)$ & $15,170(200)$ \\
\hline 2007 & $5,651(23)$ & $6,743(180)^{*}$ & $0.2(0.2-0.4)$ & $8(0)$ & $1(0)$ & $12,403(112)$ \\
\hline 2008 & $4,846(24)$ & $7,068(104)^{*}$ & $0.3(0.2-0.5)$ & - & - & $11,914(128)$ \\
\hline Total & $30,210(227)$ & $54,919(653) *$ & $0.6(0.5-0.7)$ & $48(0)$ & $10(00)$ & $85,187(880)$ \\
\hline
\end{tabular}

Table 4. Sex distribution of cases and deaths of Salmonella-associated diseases from1999 to 2008 in Lagos

\begin{tabular}{|c|c|c|c|c|c|c|}
\hline Years & $\begin{array}{l}\text { Number of } \\
\text { cases in males } \\
(\%)\end{array}$ & $\begin{array}{l}\text { Number of } \\
\text { cases in females } \\
(\%)\end{array}$ & Total Cases & $\begin{array}{l}\text { Number of } \\
\text { deaths in } \\
\text { males }(\%)\end{array}$ & $\begin{array}{l}\text { Number of } \\
\text { deaths in } \\
\text { females }(\%)\end{array}$ & Total deaths \\
\hline 1999 & $1,049(2.1)$ & $703(2.0)$ & 1,752 & $17(56.7)$ & $13(43.3)$ & 30 \\
\hline 2000 & 799 (1.6) & $1,159(3.2)$ & 1,958 & $11(44.0)$ & $14(56.0)$ & 25 \\
\hline 2001 & $2,865(5.7)$ & $1,255(3.6)$ & 4,120 & $7(58.3)$ & $5(41.7)$ & 12 \\
\hline 2002 & $2,039(4.1)$ & $1,359(3.8)$ & 3,398 & $8(72.7)$ & $3(27.3)$ & 11 \\
\hline 2003 & $5,336(10.7)$ & $3,561(10.1)$ & 8,897 & $46(59.0)$ & $32(41.0)$ & 78 \\
\hline 2004 & $9,236(18.6)$ & $4,114(11.6)$ & 13,350 & 105 (61.8) & $65(38.2)$ & 170 \\
\hline 2005 & $6,545(13.1)$ & $5,680(16.1)$ & 12,225 & $55(48.3)$ & $59(51.7)$ & 114 \\
\hline 2006 & $6,322(12.7)$ & $8,848(25.0)$ & 15,170 & $94(47.0)$ & $106(53.0)$ & 200 \\
\hline 2007 & $7,229(14.5)$ & $5,174(14.6)$ & 12,403 & $70(62.5)$ & $42(37.5)$ & 112 \\
\hline 2008 & $8,384(16.8)$ & $3,530(10.0)$ & 11,914 & $79(61.7)$ & $49(38.3)$ & 128 \\
\hline Total & $49,804(100)$ & $35,383(100)$ & 85,187 & $492(55.9)$ & 388 (44.1) & 880 \\
\hline
\end{tabular}


Table 5. Distribution of Salmonella-associated diseases in different age groups

\begin{tabular}{|c|c|c|c|c|c|c|}
\hline \multirow[t]{2}{*}{$\begin{array}{l}\text { Age in } \\
\text { years }\end{array}$} & \multirow{2}{*}{$\begin{array}{l}\text { Number of } \\
\text { cases with } \\
\text { Salmonella- } \\
\text { associated } \\
\text { diseases } \\
\text { (deaths) }\end{array}$} & \multirow{2}{*}{$\begin{array}{l}\text { Number of } \\
\text { cases with } \\
\text { Typhoid fever } \\
\text { (deaths) }\end{array}$} & \multicolumn{2}{|c|}{$\begin{array}{l}\text { Number of cases with Salmonella- } \\
\text { associated gastroenteritis (deaths) }\end{array}$} & \multirow{2}{*}{$\begin{array}{l}\text { Number of } \\
\text { cases with } \\
\text { septicemia } \\
\text { (deaths) }\end{array}$} & \multirow{2}{*}{$\begin{array}{l}\text { Number } \\
\text { of cases } \\
\text { with } \\
\text { psychosis } \\
\text { (deaths) }\end{array}$} \\
\hline & & & Non-invasive & Invasive & & \\
\hline $0-10$ & 9230 (139) & $5337(76)$ & $3876(59)$ & $17(4)$ & $0(0)$ & $0(0)$ \\
\hline $11-20$ & $6249 \quad(161)$ & $1513(26)$ & $4730(135)$ & $0(0)$ & $6(0)$ & $0(0)$ \\
\hline $21-30$ & 42105 (347) & $14903(72)$ & $27176(275)$ & $0(0)$ & $24(0)$ & $2(0)$ \\
\hline $31-40$ & 13611 (139) & $4986(30)$ & 8608 (109) & $0(0)$ & $13(0)$ & $4(0)$ \\
\hline $41-50$ & $7624(60)$ & $2701(16)$ & $4917(44)$ & $0(0)$ & $3(0)$ & $3(0)$ \\
\hline $\begin{array}{l}50 \text { and } \\
\text { above }\end{array}$ & $6368(35)$ & $770(8)$ & $5595(27)$ & $0(0)$ & $2(0)$ & $1(0)$ \\
\hline Total & $85187(880)$ & 30210 (227) & $54902(659)$ & $17(4)$ & $48(0)$ & $10(0)$ \\
\hline
\end{tabular}

high incidence of SADs in areas most exposed to environmental contaminations, especially Ikeja, Ikorodu, Surulere, Ebute-Metta and Yaba. Contaminated drinking water has been documented to be one of the main sources of the disease transmission in Lagos [20]. This study was consistent with the separate findings of Khanum et al. [21] and Rustam et al., [22] which reported high incidence of SADs among patients residing in rural and more congested areas with poor sanitation.

Interestingly, both typhoid fever and gastroenteritis showed an increasing trend in both sexes between 1999 and 2001. The increase in trends of both diseases was recorded in male subjects between the years 2002 and 2006 and in female subjects between the years 2003 and 2004. These findings were similar to those observed in a study conducted in northern Nigeria where more males were implicated but the sex-related difference in infection rates did not vary significantly $(\mathrm{P}<0.05)$ [7]. A higher incidence of SADs was reported among female patients in a study conducted in Pakistan, [21], which was consistent with the case patients recorded in 2006 in the present study (Table 4). Limited dietary choices along with poor personal hygiene and open-air defecations and urination among the subjects studied were the likely reasons identified for the infections.

Salmonella-associated diseases occurred in all age groups in this study (Figure 2), with young adults (21 to 30 years) being the age group most at risk of infection, occurring in $49.49 \%$ of the patients. The few cases of patients with invasive Salmonellaassociated gastroenteritis that were observed were found mainly in children under five years of age. Also, infants and children aged 0-10 years was the third age group most affected by SADs; this group accounted for $17.7 \%$ of the cases and $33.5 \%$ of the deaths from typhoid fever in this study (Table 5). Available information revealed that most of the infants were either breastfed for a period of one to three months or in some cases, not breastfed at all but mostly fed with baby food cereals. Studies elsewhere have demonstrated that infants infected with Salmonella are less likely to be breastfed and more likely to have a household member with diarrhoea than healthy infants [23-25], situations that could not be ruled out in this study. A report from northern Nigeria had implicated young adults within the 11 to20 years and 21 to 30 years age groups to be the most vulnerable members of the community [7]. In other parts of the world, SADs particularly typhoid 
fever, has been known to be a disease of the schoolaged children and young adults and milder in infants [4]. The incidence of laboratory-confirmed nontyphoidal Salmonella infection is much greater in infants than in other age groups [4]. Infants have also been reported to suffer substantial morbidity from invasive Salmonella [2]6 and are at higher risk of complications from Salmonella-associated diarrhoeal disease [26]. In Pakistan, the highest incidence of Salmonella infection among children and infants aged 1 to 14 years has been reported [21]. A high percentage $(13 \%)$ of typhoid fever complications in children was also found in Morocco [27] and in Egypt; children were the group most affected in outbreaks of typhoid fever and other SADs [28]. Therefore, the high rate of SADs, particularly typhoid fever, recorded in infants and children in this study calls for serious concern and the implication is the increasing childhood mortality arising from these preventable diseases if unchecked.

In conclusion, the current surveillance data indicated high incidence of SADs in areas exposed to environmental contaminations. The mean incidence of SADs in Lagos was found to be 45 cases per 100.000 persons per year, while that of typhoid fever alone was 16 cases per 100,000 persons per year. Cases of patients with invasive Salmonella-associated gastroenteritis, mainly in children under five years of age, were observed. The results also revealed that infections caused by Salmonella enterica serovars are endemic in our environment and thus pose a serious threat to public health. Therefore, the need to enhance the Salmonella surveillance through collaborative strategies aimed to stem the increasing tide of SADs is advocated. Improvement in the provision of clean water and sanitation are critical to reduce the overall burden of these diseases. Constant public health education campaigns are essential to avert undue epidemics. Further population-based studies are still needed. Meanwhile, information from this study will not only support and assist the policy makers and health authorities in proper planning, but also in the prevention and control of these diseases.

\section{Acknowledgements}

The authors are grateful to the management and the staff of the various hospitals for their co-operation and moral support. Our appreciation also goes to Lagos State Ministry of Health for the co-operation received throughout the period of study.

\section{References}

1. Huang DB, Herbert L, DuPont K (2005) Problem pathogens: extra-intestinal complications of Salmonella enterica serotype Typhi infection. Lancet Infectious Diseases 5: 341348.

2. Ackers M L, Puhr ND, Tauxe RV, Mintz ED (2000) Laboratory-based surveillance of Salmnonella serotype Typhi infections in the United States; antimicrobial resistance on the rise. JAMA 283: 2668-2673.

3. World Health Organization (2005) Drug-resistant Salmonella.

http://www.who.int/mediacentre/factsheets/fs139/en/. Accessed April 2007.

4. Centers for Disease Control and Prevention (2005) FoodNet Annual Report, 2003; Atlanta, GA, USA. 356-362

5. Akinyemi KO, Smith SI, Oyefolu AO, Coker AO (2005) Multidrug resistance in Salmonella enterica serovar Typhi isolated from patients with typhoid fever complications in Lagos, Nigeria. Public Health 119: 321-327.

6. Talabi H A (1994) Medical aspects of typhoid fever in Nigeria. Nig Post grad Med J 1: 51-56.

7. Ameh I G and Opara WEK (2004) Typhoid: a record of cases in Sokoto, Nigeria. Pak J Biol Sci 7: 1177-1180.

8. Cowan ST and Steel S (1993) Identification of family Enterobacteriaceae. In: barrow GI, Felthan RKA, editors. Manual for the identification of medical bacteria. Cambridge: Cambridge University Press; p.32.

9. Akinyemi KO, Bamiro B, Coker AO (2007) Salmonellosis in Lagos Nigeria: Incidence of Plasmodium falciparumassociated co-infection, patterns of antimicrobial resistance, and emergence of reduced susceptibility to fluoroquinolone. J Health Popul Nutr 25: 351- 385.

10. Karuiki S, Revathi G, Kariuki N, Mwituria J, Muyodi J, Githinji JW, Kagendo D (2006) Multidrug -resistant nontyphoidal Salmonella infection in Africa: zoonotic or anthroponotic transmission. J A Med Microbiol 55: 585591.

11. Pathom S (2005) National Annual report on Salmonella and Shigella. The Center, National Institute of Health, Department of Medical Sciences, Ministry of Public Health, Nonthaburi, Thailand. pp12.

12. Onyango MD, Ghebremedhin B, Waindi EN, Kakai R, Rabsch W, Tietze E, Konig W, Konig B (2009) Phenotypic and genotypic analysis of clinical isolates Salmonella serovar Typhimurium in Western Kenya. J Infect Dev Ctries 3: 685-694.

13. Rasaily R, Dutta P, Saha MR, Mitra U, Lahiri M, Pal SC (1994) Multiple drug resistant typhoid fever in hospitalized children: clinical,bacteriological and epidemiological profiles. Eur J Epidemiol 10: 41-46.

14. Kothari A, Pruithi A, Chugh TD (2008) The burden of enteric fever. J Infect Dev Cries 2: 253-259.

15. Ghenghensh KS, Franca E, Tawil K, Wasfy MO, Ahmed SF, Rubino S Klena JD (2009) Enteric fever in Mediterrranean North Africa. J Infect Dev Cries 3: 753-761.

16. Centre for Information and Development (CID) (2006) Annual report, CID, Secretary of Health and Environment, Libyan Arab Jamahiyria. 12-14.

17. Afifi S, Earhart K, Azab MA, Youssef FG, El Sakka H,Wasfy M, Mansour H, El Oun S, Rakha M, Mahoney F (2005) Hospital-basedsurveillance for acutefebrile illness in Egypt: a focus oncommunity-acquired bloodsrteam infections. Am J Trop Med Hyg 73: 392-399. 
18. Ministere de la Sante Publique (MSP) Tunisien (2006) Bulletin Epidemiolologique Annuel du Ministere dela Sante Publique Tunisien. 26 -28.

19. Crump JA, Youssef FG, Luby SP, Wasfy MO,Rangel JM, Taalat M, Oun SA Mahoney FJ (2003) Estimating the incidence of typhoid fever and other febrile illnesses in developing countries. Emerg Infect Dis 9: 539-544.

20. Akinyemi KO, Iwalokun BA, Foli F, Oshodi K, Coker AO (2011) Prevalence of multiple drug resistance and screening of enterotoxin (stn) gene in Salmonella enteric serovars from water sources in Lagos, Nigeria. Public Health 125: 65-71.

21. Khanum, S, Saba, NV, Qayyum, My Islam B, Qazilbash AA (2006) Distribution patterns of Salmonella infection in Rawalpindi/Islamabad area and the risks factors associated with the disease prevalence. J Biol Sci 6: 253-260.

22. Rusttam S, Saba M, Qayyum M, Islam Bu, Qazubash (2006) Enterobacteriaceae: Etiological agents of Diarrhoeae. J Med Sci 6: 149-154.

23. France GL, Marmer DJ, Steele RW (1980) Breast feeding and Salmonella infection. Am J Dis Child 134: 147-152.

24. Haddock RL, Cousens MA,Guzman CC (1991) Infant diet and salmonellosis. Am J Public Health 81: 997-1000. Haddock RL, Cousens MA,Guzman CC (1991) Infant diet and salmonellosis. Am J Public Health 81: 997-1000.

25. Delarocque-Astagneau E, Desenclos JC Bouvet P, Grimont PAD (1998) Risk factors for the occurrence of sporadic Salmonella enterica serotype enteritidis infections in children in France: a national case-control study. Epidemiol Infect 121: 561-567.

26. Bouskraoui M, Zineddine A, Dehbi F, Najib J, Benbachir M, Abid A (2000) Les complications de la fievret yphoide chez l'enfant. Med Mal Infect 30: 146-151.

27. El Sherbini A (1992) An outbreak of typhoid fever resistant to chloramphenicol and other drugs in Gharbeya Governorate in Egypt. J Trop Pediatr 38: 331-334.

28. Cleary, TG (2004) Salmonella. In: Feigin RD, Cherry JD, Demmler GJ, Kaplan SL. Editors, Pediatric Infectious Diseases 5th ed. Philadelphia, PA: WB Saunders Co 14731487.

\section{Corresponding author}

Akinyemi K O (PhD)

Department of Microbiology

Lagos State University

PMB 1087

Apapa, Lagos

Nigeria

Telephone:+2348029088676; 07038127529

Fax:

Email: akinyemiko@yahoo.com

Conflict of interests: No conflict of interests is declared. 